\title{
19
}

\section{Benchmarking for education managers}

\author{
J.D. Warwick \\ SIMS Education Services Ltd \\ Priory Business Park, Cardington, Bedford, MK44 3SG, England \\ Phone: (44)-1234-838080 Fax: (44)-1234-838091
}

\begin{abstract}
Central Governments have always collected education data to inform the formation of policies and decision making. The world wide trend of decentralising education systems is resulting in an increasing amount of source data being located in schools. In addition, decentralisation gives rise to the need for Central Government to analyse data in a manner that can provide information on the relative performance of Regional Governments or individual schools. Decentralised educational systems have a double challenge; how to collect data without placing too great a burden on schools and how to supply education leaders and managers at the school level with information that will support them in their policy formation, decision making and performance management. Drawing on experience in the United Kingdom, the paper identifies ways in which information and communication technology can meet this challenge and, using examples of recently developed software, identifies the benefits of making national information available in a format that enables schools to easily benchmark their inputs, processes and outcomes.
\end{abstract}

Keywords

Education management, evaluation/formative, future developments, government, national policies, self assessment

\section{INTRODUCTION}

Monitoring and evaluation are essential to good strategic management and effective managers seek to build into their organisational systems, procedures that enable them to receive relevant and accurate feedback on how the organisation is operating and what it is achieving. Central governments compile statistics to report on the functioning of the education system and to provide aggregated data for policy makers and strategic planners. In centralised educational systems most of the source data is held within the Ministry of Education. However, as in most organisations "much of the information is dispersed, inconsistent, incompatible and inaccessible" (ICL, 1992, 9). One of the key findings of a major research project on 'Management in the 1990s' conducted by the 
Sloan School of Management at the Massachusetts Institute of Technology was that integration provides the main opportunities for improving business effectiveness: "Various forms of integration are at the heart of many of the necessary changes. It is not just a matter of combining databases or using a common database across all the departments of an organisation. It covers the wider issues of achieving close and effective working relationships between various parts of an organisation, for example in terms of structure, working relationships, common or inter-linked processes and shared information. Integration will be essential both within an organisation and across organisational boundaries" (op cit, 8).

The need for integration over and above the creation of similar databases is an important insight but creates difficulties in a climate, such as education, where there is a world wide trend to decentralise and delegate responsibility to front line institutions, namely schools. Such self managing organisations can set up administrative and management structures best suited to local needs. Difficulties may arise when data needs to flow between organisational boundaries. As an example, consider the issue of reporting on spending patterns. In a centralised system all financial details are likely to be held at the centre with ledger codes and cost centres set up to meet central strategic management needs. Reporting on expenditure patterns is a relatively easy task. Self governing schools in England and Wales can create their own ledger codes and cost centres with no guarantee that the same headings mean the same in each school or that similar transactions will be coded in the same way. The process of providing feedback to managers at the centre becomes difficult or costly at all levels in the system as alternative and often parallel forms of data collection need to be instigated.

\section{COLLECTING EDUCATIONAL DATA IN A DELEGATED SYSTEM}

Data gathering is a difficult task even when most of the data is at one level of government. In larger countries, with regional levels of Government exercising varying amounts of responsibility for policy formation and decision making, collecting data becomes even more costly because of the proliferation of disparate systems and because the data may be formatted in ways to meet local rather than central needs. When management responsibilities are delegated to the school level, the problems of data collection are considerably magnified because much of the source data will be in schools. In any system that relies on paper returns, validation has to take place at the centre and much time and energy can be taken up in entering data, chasing late returns or in querying inaccuracies.

Collecting accurate data has always been a time consuming and expensive task made worthwhile only if the resulting information has a value and leads to some action for improvement. The problem within delegated systems is that the cost of collecting data falls on schools, whilst most of the value is derived at the centre because it is the centre that determines the indicators to be used and publishes the information at a time and in a format useful to central government.

Data will always be required to flow to Central Government in order to provide feedback to strategic managers. In delegated systems, equivalent data is also required at the level of local government or school: education managers at all levels need information to enable effective policy formation and decision making. Feedback can be concerned with absolute measures, for example Ministries of Education regularly produce demographic or financial reports. Such information clearly has a role, particularly when systematically collected and reported as part of a longitudinal study in order to determine trends. The value of such information increases if schools are able to make comparisons with other, similar, institutions. 
This is the principle of benchmarking which has been described as "an external focus on internal activities, functions or operations in order to achieve continuous improvement" (Liebfried \& McNair, 1994, 1). Although the concept of benchmarking is not new to education, its use is certainly not widespread and is often limited to international reports comparing performance across countries. One reason for this may be the basically centralist nature of education systems, with all schools being seen to operate the same procedures. In countries where regional government or schools are involved in policy formation and strategic planning, central government will also seek to compare inputs, processes and outcomes in order to inform choice and learn from best practice. In England and Wales, for example, the Government is keen to compare the performance of different local education authorities and schools and to publicise the results. All political parties are committed to making more information available to the public and there is unlikely to be any decrease in the amount of information that is now being made available. Indeed, it is likely to increase. As an example, school inspection reports are now available on the Internet (http://www.open.gov.uk /ofsted/ofsted.htm).

Collecting data in order to publish information about the performance of individual schools requires the highest level of accuracy and validation. and the exercise has the potential for being very costly. Initial attempts, in England and Wales, to collect data from third parties, such as examination boards, caused considerable problems because schools challenged the accuracy of the published figures. Additional costs have had to be borne in order to check and negotiate the figures with schools prior to publication. Local management and self governance have been welcomed by schools in the UK; what has not been is the perceived increase in bureaucracy and collection of data with minimal tangible benefits to those supplying the data.

\section{AN INFORMATION TECHNOLOGY SOLUTION}

The challenge faced by decentralised educational systems is to make the whole process of providing feedback to strategic and tactical planners at all levels in the system more productive. This challenge can be broken down into two basic issues; how to collect accurate and validated data in the least inconvenient way to schools and at least cost; and how to make the resulting information available in a form that is of most value to schools and Local Education Authorities, which means feeding back data in a manner that enables internal development.

A potential solution lies in the use of information and communication technology, not only for collecting data but for benchmarking and feeding back results in a format that enables an institution to privately compare the fine details of its performance against similar institutions. Whilst benchmarking is a powerful tool for continuous improvement, when combined with gap analysis, significant gaps in performance between similar institutions can be the catalyst for paradigm shifts in an organisation, particularly if a culture can be established in which institutions who perform well are prepared to be identified and share their processes with others.

Within the UK, IT is playing an ever increasing role in education management. The most popular education management information system (EMIS) is that developed by SIMS (http://www.sims.co.uk/) with a user base of approximately 85 percent of schools in England, Northern Ireland and Wales. This market penetration, resulting in over 21.000 schools using the system in 121 local education authorities, means that the company is well informed of user needs and is able to make representation to government agencies for the move to electronic forms of data collection. The SIMS system is an integrated suite of modules covering all of the business processes of schools and colleges. In addition, its education authority system (EMS) has the facility to transfer data to and from the school's system. Electronic forms of data capture are now becoming a reality. Each year, the Department for Education and Employment 
(DfEE) and the Department of Education in Northern Ireland (DENI) issue forms for the collection of educational census data from schools. In the past, this paper exercise has taken a senior member of staff of the school up to two weeks to complete. Even then, staff at the DfEE have had to enter the data onto their computer systems, run validation checks and seek clarification from the school. SIMS now co-operates with the DfEE and DENI so that each year software is written to collect the relevant data from the school's EMIS. Where required processing of data is done locally and when the software has to use some intelligence to gain an answer the user is asked to confirm the entry. A major advantage of this approach is local validation and the ease with which data can be input at the centre. More than 250 validation checks are carried out, local users are informed of inconsistencies and asked to check their data. The resulting output can be sent to the DfEE either on disk or through electronic data interchange (EDI). In January 1996 it is estimated that over 14000 schools returned their census data through electronic means. Whilst the saving in time for the DfEE and DENI is substantial, at the school level the time to complete the return can be as low as 20 minutes.

Similar exercises are now taking place with other government agencies, such as the collection of returns on students performance in public examinations and national curriculum assessments as well as the compilation of performance measures prior to the inspection of a school. All the required data can be drawn from the school's database, validated, processed locally and returned electronically. There are still challenges to overcome, particularly where schools have had the freedom to store data in formats of their own choosing, such as in the area of finance. One solution is to build into the software mapping processes which enable the school's ledger codes to be nested in or split between centrally defined codes. The software is given some intelligence to make guesses as to these mappings which can be confirmed by the user. The solution is not ideal, but the fact is that schools and local education authorities are unlikely to agree to give up their freedom to organise their data in a form most appropriate to them unless there is some pay off in return, such as valuable benchmarking information.

The move to efficient electronic data collection has been made possible by the fact that practically all schools in the UK now use an EMIS and the vast majority have chosen to use the same integrated system, thus providing resources to produce new versions of the software to meet the ever changing needs of Government. Secondly, the Government and its agencies have recognised that an IT solution is the only way in which they would be able to transfer data to and from a large number of schools and therefore agreed to inform software houses of changes in time for the new requirements to be coded and disks distributed. Finally, Government Agencies have set up internal systems to receive the data.

\section{BENCHMARKING FOR INTERNAL REVIEW}

Whilst IT has enabled central government to acquire the data it needs for measuring inputs, processes and outputs there is now a case for using the national data in a creative way to help schools and local education authorities in their strategic management processes. The challenge is to make the vast amounts of data collected by central government and its agencies available in ways that will enable schools to compare the detail rather than the headlines of their performance against similar schools. The process to make this happen is quite straightforward and has already been employed by SIMS to produce diagnostic and performance analysis software for benchmarking national assessments.

In one module, data from a large number of schools is statistically modelled to identify the relationship between students' performance at the General Certificate in Secondary Education (GCSE) and specific ' $A$ ' level subjects, which are taken by students two years later than GCSE. The resulting regression equations vary by subject 
and gender. By enabling schools to calculate their own regression lines it is possible to compare performance in a variety of ways. In another module, the school enters the marks gained by each student to each question in a national assessment. The software enables a diagnostic report to be produced of the student's performance as well as supplying tools to enable benchmarking against the national performance of students.

In the first module, SIMS acts as the collecting bureau. Schools in the project are supplied with software that automatically validates and collects, from the SIMS system, all the data that is required for creating the statistical model. The data is sent to SIMS, either on disk of through EDI. The incoming data is processed to determine all the relevant coefficients in the model. This "picture" of the national database is then transferred to a program which is sent to the schools and colleges in the project. On installation the program re-collects the local data to create equivalent local "pictures" of performance. The software then enables a variety of comparisons to made between or within the local and national 'pictures'. The software allows various forms of filters to be applied so that 'what if ...?' questions can be asked.

In the second module, national statistics are supplied to SIMS by the government agency responsible for assessment. Individual student data is entered by keyboard or through specially designed optical mark reader forms. Once data has been entered the school is able to analyse its performance using sophisticated statistical tools hidden behind simple graphical presentations. Both processes have a number of key features.

- Feedback is being given on data that has to be presented to the centre.

- Taking part involves minimal extra work.

- Feedback is quick so that performance can be analysed when the issue is alive.

- Schools can ask a variety of "what if" questions and even use the software as a basis for setting targets for future cohorts of students.

- Schools own their data; all analysis is undertaken by the school.

A further practical example where data is used for benchmarking is in the process of inspecting schools. Government Inspectors collect data from a variety of sources to form an extensive database of information about each school. Statistical modelling techniques are used to create various classifications of schools. Indicators are selected such as examination results, attendance, expenditure patterns, curriculum structures, staffing levels and so on and the expected range of performance is identified for each school that is to be inspected using the results of the national model but taking into account the context of the school. The resulting report provides background information for the inspection team which is also shared with the school.

\section{CONCLUSION}

As more countries move to decentralise their education systems, information technology can provide the solution for collecting accurate and validated data that does not place unrealistic demands on schools. However, increasing delegation also means that schools need to have access to information that enables them to fulfil their strategic management role. In delegated systems schools will begin to demand some return for supplying their data.

The two examples in this paper show that it is feasible to produce software that contains models of national data that can be used as benchmarks against which schools can compare their performance using a variety of interrogation techniques. As such, education managers, at all levels of the system can be supplied with information to help them formulate policies, plan strategically and measure performance. The availability of such information will provide the return that schools seek and recompense the cost of supplying data in the first place. At present it is necessary to create "pictures" that 
represent the national data and in so doing software designers determine the parameters to be analysed. With the advent of the superhighway it will be feasible for schools to directly interrogate national education databases, pulling down the results into local analysis generators. When that happens we can truly believe that we have moved from making census returns on paper, a time before computers $(\mathrm{BC})$ to a time when the focus moves from simply adding data $(\mathrm{AD})$ to the provision of information which is valued and used by schools.

\section{REFERENCES}

ICL (1992) A Window on the future. ICL, London Liebfried \& McNair (1994) Benchmarking. Harper Collins. London.

Office for Standards in Education (1996) On the WWW at http://www.open.gov.uk/ ofsted/ofsted.htm

SIMS (1996) On the $W W W$ at http//www.sims.co.uk/

\section{BIOGRAPHY}

John Warwick taught mathematics and information technology in a variety of schools before becoming an inspector of schools. From the position of Chief Inspector for Schools in Bedfordshire he moved to the post of Assistant Chief Education Officer. John has been involved in the development of educational management information systems for over 16 years and was a member of the original team that conceived of SIMS in 1981. Within the company John has specific responsibility for international developments and as such has also acted as a consultant for a variety of aid organisations. John also contributes to new product developments and identifies new opportunities for the company in the developing field of ITEM. 